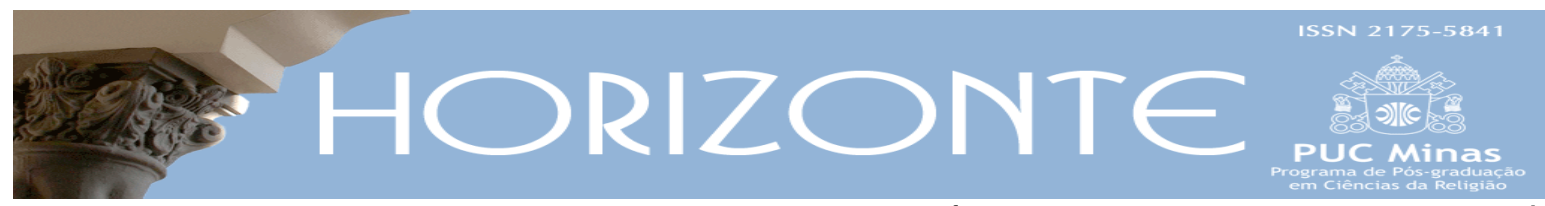

Temática Livre - Artigo original

DOI - 10.5752/P.2175-5841.2015v13n38p878

\title{
O Êxodo como tradição de Israel Norte, sob a condução de El e Javé na forma de touro jovem
}

\author{
The Exodus as a tradition from Northern Israel, under the leadership of El \\ and Yahweh in the form of young bull
}

José Ademar Kaefer*

\begin{abstract}
Resumo
O Êxodo é uma das tradições fundantes de Israel e Judá. Porém, se Israel enquanto povo é oriundo de Canaã, como entender o processo de libertação do Egito? O artigo busca mostrar que a tradição do Êxodo se formou em Israel Norte, possivelmente durante o domínio egípcio de Sheshong I (945-925), campanha que se encontra registrada nos muros do templo de Karnak, no Egito, o qual derrocou o nascente reino de Saul. $O$ artigo mostra também que nos santuários de Betel, Siquém e Dã havia um culto a uma divindade representada na imagem de um touro, a quem era atribuída a libertação do Egito. No princípio essa divindade era o Deus El, mais tarde, porém, passou a ser o Deus Javé, que absorveu os atributos de El, inclusive o culto na forma de touro. A caminhada pelo deserto é uma tradição independente e só mais tarde foi anexada à tradição da libertação do Egito. É possível que ela tenha surgido em Kuntillet 'Ajrud, um entreposto para cobrança de tributo situado no deserto do Sinai e dominado por Israel Norte durante o reinado de Jeroboão II, na primeira metade do século VIII a.C.
\end{abstract}

Palavras-chave: Êxodo; Israel Norte; El; Javé; Touro; Kuntillet ‘Ajrud.

\begin{abstract}
Exodus is one of Israel's and Juda's foundation traditions. However, if Israel as a people emerged in Canaan, how does one understand the liberation from the Egypt tradition? The article tries to show that the Exodus tradition was formed within Northern Israel, maybe during the Egyptian domination of Sheshong I (945-925), a campaign that is registered in the temple of Karnak, in Egypt, that defeated the fragile rein of Saul. The article tries to show also, that in the sanctuaries of Betel, Shechem and Dan there existed a cult to a divinity represented by a bull image, to whom was attributed the liberation from Egypt. At the beginning this divinity was the God El, but later, it passed to be the God Yahweh, who absorbed the attributes of El, including the bull cult. The wandering through the desert is an independent tradition, and it was attached to the liberation tradition only later. It's possible that this tradition was form in Kuntillet 'Ajrud, a center for tribute collecting, situated in the desert of Sinai and dominated by Northern Israel, during the reign of Jeroboam II, in the first half of the VIII century a.C.
\end{abstract}

Keywords: Exodus; Northern Israel; El; Yahweh; Bull; Kuntillet 'Ajrud.

Artigo recebido em 30 out. 2014 e aprovado em 01 de junho de 2015.

* Doutor em teologia bíblica pela Westfälische Wilhelms-Universität Münster, Alemanha. Professor titular de Antigo Testamento do Programa de Mestrado e Doutorado em Ciências da Religião da Universidade Metodista de São Paulo (UMESP). País de origem: Brasil. E-mail: jademarkaefer@yahoo.com.br

Horizonte, Belo Horizonte, v. 13, n. 38, p. 878-906, abr./jun 2015 - ISSN 2175-5841 


\section{Introdução}

Desde século IXX, o estudo literário da Bíblia, tendo como aliados principais, a partir do século XX, o Método Histórico Crítico e a arqueologia, vem desconstruindo e reconstruindo teorias sobre a história de Israel. Uma das mais impactantes desconstruções foi, sem dúvida, a da teoria da conquista da terra prometida, narrada principalmente no livro de Josué. Após os estudos, como os de Martin Noth (Das System der zwölf Stämme Israels, 1930) e Albrecht Alt (Kleine Schriften zur Geschichte des Volkes Israel, 1953), entre outros, sobre a ocupação lenta de Canaã (teoria da migração), seguidos da teoria de George Emery Mendehall (The Tenth Generation: The Origens of the Biblical Tradition, 1973) e Normann K. Gottwald (The Tribes of Yahweh - A Sociology of the Religion of Liberated Israel - 1250-105O B.C.E.), 1979) sobre a revolta camponesa contra as cidades-estado cananeias, influenciados pelas transformações sociais e políticas na América Latina, especialmente de Cuba e Nicarágua, chegou-se praticamente a uma unanimidade de que Israel surgiu em Canaã. Ou seja, nenhum estudo sério hoje em dia aceita mais que Israel seja uma espécie de nação extraterrestre que se instalou em Canaã vindo de fora. Pelo contrário, o Israel bíblico é essencialmente cananeu. Isso evidentemente tem tido e continua tendo reflexos sobre a situação geopolítica pela qual passam Palestina e Israel. Ultimamente a teoria que vem sofrendo forte revés, com os estudos principalmente de Israel Finkelstein e Neil Asher Silberman (The Bible Unearthed, 2001; David and Salomon, 2006), é o da Monarquia Unida.

Se Israel surgiu em Canaã, como fica a história ou a tradição do Êxodo, tida como experiência fundante de Israel? No início, após o surgimento das primeiras teorias, no intuito de salvaguardar a participação do Êxodo na formação do povo de Israel, argumentava-se que só um pequeno grupo, sob a direção de um líder (Moisés?) e a condução de um Deus (Javé?), teria fugido da opressão egípcia e se unido aos rebeldes cananeus e aos imigrantes extra-palestinenses nas montanhas 
do Planalto central de Canaã. ${ }^{1}$ No entanto, esse pequeno grupo, dada as dificuldades de se fundamentar sua passagem pelo deserto do Sinai, sem ser detectado pelas unidades de controle egípcias, foi sendo diminuído cada vez mais até quase desaparecer ou de ficar difícil de sustentar tal hipótese. Enfim, a dúvida não foi resolvida: se Israel surgiu em Canaã, de onde veio a tradição do Êxodo? Essa dúvida aumentou com as recentes descobertas e conclusões arqueológicas de que Judá teve um desenvolvimento tardio. Isto é, Judá, enquanto reino com estrutura burocrática básica para a cobrança de tributos etc., só se desenvolveu no final do século VIII, depois da queda da Samaria (722 a.C.). É a partir desse período que Judá se expande para o sul e para o oeste, as montanhas começam a ser habitadas e a cidade de Jerusalém cresce extraordinariamente em população. É também quando começam a serem encontradas as famosas phitoi, grandes jarros com a marca lemelek "para o rei', prova do surgimento de uma estrutura monárquica para a cobrança de tributo, e de um corpo de escribas que organizava as contas da corte. Ou seja, a escrita em Judá praticamente surge nesse período. Esse fato tira qualquer possibilidade remota de localizar o Êxodo por volta de 1200 a.C, onde ele foi tradicionalmente localizado. Portanto, não só a saída do Egito é posta em xeque, mas também a rota pelo deserto do Sinai, no sul de Judá, e sul da Transjordânia, território totalmente desconhecido antes do século VIII.

Para o nosso ensaio em busca de respostas para a pergunta formulada acima, iremos nos fundamentar inicialmente em alguns textos bíblicos e depois olharemos para as recentes descobertas em alguns sítios arqueológicos de Israel e Palestina.

\footnotetext{
${ }^{1}$ Por exemplo, SCHWANTES,, M., “História de Israel - Local e origens”, 2008.
} 


\section{1 “Estes são teus Deuses, Israel, que te fizeram subir da terra do Egito” (Ex}

\section{$32,4 b)$}

Um dos textos de nossa análise é Ex 32, tradicionalmente conhecido como a "história do bezerro de ouro". Quando o povo viu que Moisés demorava em descer da montanha, pediu a Aarão para que lhe fizesse Deuses ('elohim) que fossem diante dele. Depois de reunir os enfeites pessoais o povo os levou a Aarão, que os fundiu fabricando com eles um touro jovem ('egel) ${ }^{2}$ de metal. Ao vê-lo, o povo exclamou: "Estes são teus Deuses, Israel, que te fizeram subir da terra do Egito" $(32,4 b)$. Essa exclamação é surpreendente, pois contradiz a tradição de que foi Moisés, junto com Javé, que tirou Israel do Egito. E ela não ocorre somente aqui, mas se repete em $32,8 c$, onde ela é colocada na boca do próprio Javé. Ou seja, por um lado, como vimos, ela é atribuída aos 'elohim na imagem de um touro jovem e outras vezes ela é atribuída a Moisés: “... pois a este Moisés, o homem que nos fez subir da terra do Egito, não sabemos o que aconteceu a ele" $(32,1 c)$; "E disse Javé a Moisés: 'vai, desce, pois se perverteu teu povo que fizeste subir da terra do Egito" $(32,7)$. Portanto, aparentemente temos aqui duas tradições que divergem sobre a saída da terra do Egito. Se assim, qual delas é mais antiga ou qual foi cooptada?

Além das versões divergentes sobre o Êxodo, o texto revela também a presença de uma antiga tradição de culto a uma divindade na imagem de um "touro jovem” a quem se atribui a saída do Egito: "E os (pingentes) joguei no fogo e saiu este touro jovem ('egel)" $(32,24)$. Como se Aarão não soubesse o porquê de ter surgido tal imagem. O interessante é que o texto parece indicar que essa divindade na forma de um touro jovem é Javé: "Quando viu Aarão (a imagem) edificou um altar diante dele e, então, Aarão gritou e disse: 'amanhã será festa para Javé” $(32,5)$. Na manhã seguinte o povo madrugou ofereceu holocaustos e ofertas de paz, comeu, bebeu e depois fez festa $(32,6)$. Esse Javé, porém, parece ser diferente do

\footnotetext{
2 'egel é um touro de cerca de um ano de idade ( $\operatorname{lv}$ 9,3; Mq 6,6), por isso, optamos pela tradução "touro jovem", que nos parece mais aproximada que "bezerro", como normalmente é traduzido nas versões portuguesas.
} 
Javé cultuado em Jerusalém e difundido pelo redator deuteronomista, que reprime severamente o outro culto: "Moisés tomou o touro jovem que haviam feito e o queimou no fogo e o triturou até virar pó. Depois o espalhou sobre a superfície das águas e fez os filhos de Israel beber" $(32,20)$. O ato é semelhante ao que fez o rei Josias (640-609), quando centralizou o culto em Jerusalém e destruiu os santuários do interior (2Rs 22-23). A ira contra o culto a Javé na forma de touro é tanto que o deuteronomista atribui a ele a quebra da aliança: "Aconteceu que, quando se aproximou do acampamento e viu o touro jovem e as danças, a ira de Moisés se acendeu e ele lançou de sua mão as tábuas e as quebrou ao pé da montanha" $(32,19)$.

Pelo texto, não é possível saber claramente onde se praticava o culto abordado acima. Supostamente estamos ao pé do Monte Sinai, local onde Moisés recebeu as tábuas da lei (Ex 19,1-3). Porém, dada à redação tardia do texto, provavelmente o foco é o culto praticado em Israel Norte, nos santuários de Samaria, Siquém e Betel.

\section{2 "Eis aqui teus Deuses, Israel, que te fizeram subir da terra do Egito" (1Rs}

\section{$12,28 c)$}

Outro texto de nossa análise é 1Rs 12,26-33, tradicionalmente conhecido como “o cisma religioso entre Israel e Judá". Também aqui encontramos a expressão que faz referência à saída do Egito: "E se aconselhou o rei (Jeroboão) e fez dois touros jovens ('egeley) de ouro e disse para eles: 'É demais para vocês subirem a Jerusalém, eis aqui teus Deuses ('elohim), Israel, que te fizeram subir da terra do Egito'. E colocou um em Betel e um em Dã” (12,28-29). Também aqui temos a existência de um culto aos 'elohim na imagem do "touro jovem" ('egel). Diferentemente do texto acima, o local aqui é bem definido: em Betel, na divisa entre Judá e Israel Norte, e Dã, nos limites de Israel Norte. Apesar desses dois santuários, localizados nos limites sul e norte do território, serem santuários da 
realeza, a base de Jeroboão é Siquém, na montanha de Efraim, antiga cidade no planalto central da Samaria $(12,25)$.

Ao contrário do que tenta fazer entender o texto, os santuários de Betel e Dã são mais antigos que o santuário de Jerusalém, assim também o culto praticado ali. Ou seja, pelo texto, em primeira análise, quem muda o costume é o Norte: Siquém, Betel e Dã. Mas, na verdade, o que acontece é o oposto. Podemos comprovar isso em outros textos bíblicos, como Gn 12,6-8, onde se relata que os primeiros santuários que Abraão visitou, assim que chegou à Canaã, foram Siquém e Betel. Abraão demarcou esse território construindo ali dois altares a Javé. Um paralelo encontra-se em Gn 35,1-15, texto provavelmente bem mais antigo que $\mathrm{Gn}$ 12,6-8. Aqui Jacó constrói um altar para El e dá o nome ao santuário de "Casa de El”, que significa Betel. Para que fosse um santuário de Javé, dever-se-ia chamar Betyah (casa de Javé). Portanto, muito antes de ser de Javé, Betel foi um santuário de El.3

1Rs 12,26-33 supõe também que a Casa de Davi reinara sobre todo Israel Norte: “E disse Jeroboão em seu coração: 'agora o reino poderá voltar para a casa de Davi. Se este povo sobe para oferecer sacrifícios no templo de Javé em Jerusalém, volta o coração deste povo a seu senhor, Roboão, rei de Judá”” (12,2627). Sabe-se hoje que isso nunca foi fato, e que Judá, com sua capital Jerusalém, só se tornou forte o suficiente para tanto depois da queda Samaria, em 722 a.C. Na verdade, foi Israel Norte quem reinou sobre Judá. De forma que, se não houve "monarquia unida" sob Davi e Salomão, também não houve cisma, e tampouco necessidade de impedir o povo de peregrinar a Jerusalém.

Há ainda dois outros aspectos importantes a destacar em 1Rs 12,26-33. Um é a festa nacional celebrada em Betel: "E instituiu Jeroboão uma festa no mês oitavo, no décimo quinto dia do mês, uma festa como se celebrava em Judá, e

\footnotetext{
${ }^{3}$ Mesmo após a destruição da Samaria em 722 a.C., Betel continuou sendo um forte concorrente para o templo de Jerusalém.
} 
subiu ao altar. Assim fez em Betel para sacrificar aos touros jovens que havia feito e colocado em Betel" (12,32). A festa representa ser a festa das Tendas ou da colheita, onde o próprio Jeroboão sobe ao altar e faz a oferta, papel que em Jerusalém pertencia somente ao sacerdote. Pelo texto, a festa existia antes em Jerusalém e depois foi introduzida por Jeroboão também em Betel. No entanto, também nesse caso o processo é inverso.

Outro aspecto interessante é a acusação de que Jeroboão promovia os chamados "lugares altos" (bamot), que eram pequenos santuários populares no interior de Israel, comumente localizados em colinas e sob árvores sagradas: "E fez casa de lugares altos e fez sacerdotes dentre o povo que não eram dos filhos de Levi” (12,31). Ou seja, apesar de Betel ser um santuário nacional (Am 7,10-17), pelo texto, não havia um local de culto centralizado, como sucedia em Jerusalém, mas difundido pelo interior. Além disso, o exercício do sacerdócio (qohen), não era exclusividade de uma dinastia, como a dos descendentes de Levi ou de Sadoc, como passou a ser práxis em Jerusalém, mas tirados do meio do povo (1Rs 13,33).

Similar a Ex 32, também aqui o culto é extremamente difamado, a ele será atribuída destruição e deportação da Samaria (1Rs 13,34), e Jeroboão será o arquétipo dos reis maus que levaram Israel ao pecado.

Enfim, uma vez que os santuários de Betel e Dã, assim como Siquém, são bem mais antigos que o santuário de Jerusalém, também o culto praticado ali é mais antigo. Inicialmente parece que a divindade maior nesses santuários era El, provavelmente em companhia das divindades femininas da fertilidade, Asherá e Anat. Posteriormente, possivelmente já no reinado dos reis omridas, a divindade que foi se sobressaindo, ainda entre outras, sem a exigência monoteísta, foi Javé. Uma prova disso é a estela de Mesa, escrita pelo rei de Moab por volta de 840 a.C., onde Javé já aparece como o Deus nacional de Israel Norte (KAEFER, J. A., 2006, p. 171). Um Javé que, conforme estamos conseguindo observar, era cultuado na imagem de um touro jovem e a quem era atribuída a libertação do povo do Egito. O 
culto a esse Javé será bem mais tarde reprimido pelo culto a Javé de Jerusalém, que aos poucos não permitirá mais a parceria de outros Deuses, principalmente Deusas, e se imporá como único Deus.

\section{3 “Rejeita teu touro jovem ('egel), Samaria" (Os 8,4a)}

O terceiro texto de nossa análise é Os 8,4-7. Desde a queda da teoria das fontes (J, E, D, P), o livro do profeta Oseias é tido como um dos textos mais antigos da literatura bíblica (DE PURE, A. (Org.), 1996, p. 15-85), ou pelo menos partes dele. Uma dessas partes que parece guardar memórias de antigas práticas de Israel Norte, em particular da capital Samaria, é Os 8,4-7. Assim como em Ex 32 e 1Rs 12,26-33, também aqui temos uma grave acusação contra o culto ao touro jovem em Israel Norte. Só que nesse caso a prática acontece na capital Samaria:

\footnotetext{
"Rejeita teu touro jovem ('egel), Samaria. A minha ira se inflama contra eles. Até quando não serão capazes de inocência? Eis que ele é de Israel e foi um artesão que o fez. Ele não é um Deus. Eis que o touro jovem ('egel) de Samaria será feito em pedaços" $(8,4-5)$.
}

Entendemos que a denúncia acontece nos últimos anos de Israel Norte, pouco antes da invasão Assíria em 722 a.C., mas o culto em Samaria é certamente bem mais antigo, pelo menos já desde os tempos de Jeroboão II (788-747). A denúncia, no entanto, é procedente do sul, Judá. O Deus que fala aqui, ou em cuja boca são colocadas as palavras, é o Javé de Jerusalém. O destinatário é bem evidente: o touro jovem de Samaria. O substantivo é mencionado duas vezes e duas vezes se repete o pronome "ele". De maneira que, não há como negar a existência do culto a uma divindade na forma de um touro jovem também na capital Samaria. Portanto, a denúncia é contra o Deus nacional de Israel, que é Javé cultuado na forma de um touro jovem. 
Também aqui, como nos textos anteriores, a reprimenda a esse culto é muito forte: "Ele não é um Deus e será feito em pedaços". Parece haver muita ira na denúncia, o que leva a pensar na concorrência já assinalada anteriormente entre o santuário de Jerusalém, e os santuários de Samaria e Betel. A situação se assemelha muito com o que fizeram os reis Ezequias e Josias de Judá ao destruírem os santuários do norte de um modo muito violento (2Rs 18,1-8; 22-23).

Em sintonia com Os 6,4-7 está Os 13,2, onde também há uma forte reprimenda ao culto à divindade na forma do touro jovem: "E agora aumentaram a pecar e fizeram para eles uma imagem de sua prata segundo seu entendimento. São ídolos, tudo obra de artesãos. Deles eles dizem: homens que sacrificam e beijam os touros jovens ('egeley)”. A denúncia aqui inclui também a maneira de prestar o culto: "homens que sacrificam e beijam os touros jovens". Ritual semelhante parece ser feito a Baal em 2Rs 19,18.

Tudo indica que culto ao touro jovem em Samaria e Betel continuou mesmo depois da queda da Samaria. É isso que da a entender Os 10,5: "Pelas vacas jovens de Bet Aven tremem os habitantes de Samaria. Eis que lamenta por ele seu povo e seus sacerdotes que se alegravam por sua glória. Eis que foi arrebatada dele”. A Septuaginta traduz o substantivo plural feminino 'egelot (vacas jovens) por "bezerro", no masculino singular, o que faz sentido, pois, na frase hebraica quatro vezes se repete o sufixo pronominal masculino singular "dele", em referência ao touro jovem. De maneira que, o sujeito também deveria ser masculino singular, como no caso do "touro jovem". O local "Bet Aven" (casa do pecado) é uma referência à Betel (casa de Deus). A prática desse culto mesmo após a invasão e deportação na Samaria também é mencionada em 2Rs 17,16. 
Enfim, não há dúvidas de que também no livro de Oséias há antigas memórias do culto a uma divindade na imagem de um touro jovem praticado em Samaria e Betel.4

\section{4 “José/Efraim é o primogênito do seu touro" (Dt 33,17a)}

O quarto texto de nossa análise é Dt 33,13-17. O capítulo Dt 33, comumente conhecido como "a bênção de Moisés sobre as tribos de Israel", é um texto paradigmático para a identidade de Israel. Interessa-nos a unidade que trata sobre o dito de José (v.13-17), e mais precisamente o v.17, que diz:

“(José é o) primogênito do seu touro, glória para ele. Seus chifres são chifres de touro selvagem. Com eles ele chifra violentamente os povos até os confins da terra. E eles são as miríades de Efraim e eles são os milhares de Manassés”.

José, o mais jovem dos filhos de Jacó, é apresentado como sendo o primogênito do touro, que aqui já não é mais o touro jovem ('egel), mas o touro adulto (šor). Quem seria esse touro (šor), de quem José é o primogênito? Tudo parece indicar que é o próprio Javé. É ele que propicia a José a mais abundante das bênçãos: o mais precioso do céu e do oceano deitado embaixo, os melhores frutos do sol, da lua, as primícias das montanhas etc. (Dt 33,13-15). Uma bênção não só de fartura, mas de poder, de força e de domínio sobre os irmãos e sobre os povos da terra (v.17). O título de "primogênito do seu touro", praticamente eleva José à categoria divina: "glória para ele", o "consagrado" (nazir) entre os irmãos.

Mas, quem é José, apresentado aqui como o "filho primogênito do seu touro"? Como veremos mais adiante, José tem uma identidade confusa, não parece ter sido uma tribo, tradição literária que foi associada a Efraim.

\footnotetext{
${ }^{4}$ Temos em Oséias ainda outras referências ou denúncias aos cultos praticados em Samaria e Betel. Aliás, o livro todo está marcado pelo conflito entre Deuses. Além da disputa com o "touro jovem" de Samaria e Betel, perpassa no livro o conflito com Baal (Os 1-2) e com as divindades femininas da fertilidade (Os 4,12-14; 5,1-4; 10,1-5; 14,9). Para Os 14,9 ver a opção "eu sou tua Aserá e tua Anat".
} 
Outra questão intrigante no dito sobre José, é que ele é provavelmente oriundo de Israel Norte, assim como boa parte de todo Dt 33. No entanto, é muito estranho que, sendo originário do norte, esse texto paradigmático da identidade de Israel não tenha Efraim. Ou seja, por ser a tribo mais poderosa de Israel, tanto que Israel e Efraim são sinônimos na Bíblia, e a capital Samaria está situada na montanha do mesmo nome, Efraim deveria estar entre as tribos que recebem a bênção de Moisés. Por outro lado, Efraim, com Manassés, é atribuído como sendo remanescente de José (v.17). É bem provável, como veremos mais adiante, que José tomou o lugar de Efraim. Ou seja, na redação final da unidade, que se deu em Jerusalém, Efraim foi suprimido intencionalmente por questões ideológicas em seu lugar foi acrescentado José, que se identifica mais com Judá, como vemos em Gn 49 (KAEFER, J. A., 2006, p. 283s.). Portanto, o "primogênito do seu touro" deve referir-se a Efraim (Jr 31,9), e não a José.

À parte os detalhes literários, interessa-nos mostrar que nesse importante texto reconhecido como paradigma para a identidade de Israel, encontramos uma clara e enfática menção de Javé como o touro (šor) e que José/Efraim, a principal tribo do norte, é chamado de o "primogênito do seu touro".

\subsection{Gn 49,22-26}

Caso similar ao de Dt 33,13-17 encontra-se em Gn 49,22-26. Assim como Dt 33, Gn 49 é um texto paradigmático para a identidade de Israel. Só que, se lá era a bênção de Moisés sobre as tribos, aqui é a bênção de Jacó sobre os filhos, que no final $(49,28)$ já serão tribos. Entendemos que esse texto contém um estrato antigo (49,13-(18)24a.) que, antes de ser incorporado pela teologia judaíta de Jerusalém, que exalta a figura de Judá (49,8-12), era um texto independente e paradigmático para afirmar a identidade de Israel Norte, com louvores a Efraim. 5

\footnotetext{
${ }^{5}$ Para mais informações a respeito dessa camada antiga, recentemente enviamos um artigo para a Revista Theológica Xaveriana, Colômbia. Ali também apresentamos uma proposta de estrutura concêntrica de Gn 49.
} 
A unidade de nosso interesse são os versos 22-26, especificamente o v. 22, cuja tradução é muito complexa, pois sofreu grande interferência literária, o que exigirá de nós uma análise mais minuciosa. A tradução literal é a seguinte:

"Filho de porat é José, filho de porat junto à fonte. Filhas andou sobre/junto muro/touro".

Diferente dos demais ditos de Gn 49, este não começa com a menção do nome do filho/tribo, mas com a expressão "filho de porat", que é uma forma estranha, única na Bíblia Hebraica. Além disso, o substantivo "filhas" não combina com o verbo andar (parah). Por isso, várias e diferentes traduções têm sido feitas, que de forma geral podem ser classificadas em duas: os que traduzem porat, por planta (árvore, videira etc.) e os que traduzem porat por animal. Praticamente todas as nossas Bíblias associam porat a uma planta. Eu mesmo em outra oportunidade traduzi ben porat por "Videira jovem" (KAEFER, J. A., 2006, p. 24.193). Boa parte dos que traduzem porat por animal o identificam com o touro (GUNKEL, H., 1964, p. 485; HOOP, R., 1999, p. 180), ${ }^{6}$ que parece ser a opção correta.

Agrada-nos a tradução de R. de Hoop (1999, p. 180): "Um touro jovem é José, um touro jovem junto à fonte. No prado ele vai a passos largos para o touro”. Similar a de V. Salo (1968, p.94-95), que traduz: "filho de novilha é José. Filho de novilha na fonte, filhote de aquela que caminha junto ao touro"7.

O erro parece estar na versão massorética que leu šur "muro" do terceiro hemistíquio, em vez de šor "touro”. No hebraico sem vogais, ambas as leituras são possíveis.

\footnotetext{
${ }^{6}$ E.A. Speiser, Genesis, p.367-368, lê "filho de asno selvagem"; M. C. A. Korpel, A Rift in the Clouds: Ugaritic and Hebrew Descriptions of the Divine, UBL 8, Münster, 1990, p.532-534, traduz "filho de novilla"; A. Schökel, Dicionário bíblico hebraico-português, propõe "potro"; J. D. Macchi, Israël et ses tribus, p. 185, traduz "filho de vaca".

${ }^{7}$ V. Salo, Joseph, Sohn der Färse, BZ 12, 1968, p.94-95.
} 
Contudo, o enigma desse interessante verso ainda não está solucionado. A expressão ben porat também tem sido vista como um jogo de palavras em referência a Efraim/Efrat (SEEBASS, H., 1984, p. 334). Ou seja, porat e Efraim/Efrat têm a mesma raiz. De maneira que muitos estudiosos não titubeiam em afirmar que no princípio o "dito de José” (Gn 49,22-26) pertencia a Efraim e não a José (ZOBEL, H. J., 1965, p. 5.115; WESTERMANN, C., 1982, p.270; SANMARTIN, J., 1983, p. 92-93).

Isso explicaria a ausência de Efraim, a mais importante tribo do norte, desse que é o paradigma dos textos para a identidade de Israel. Essa possibilidade tem em seu favor a constante associação entre José, Efraim e Manassés na Bíblia Hebraica, especialmente no Pentateuco. ${ }^{8}$ Em contrapartida, raramente encontramos menção a José como tribo, mas como casa, "a casa de José”, em sintonia com “a casa de Judá”. Em síntese, entendemos que José, enquanto tribo, é uma produção literária de escribas jerusalemitas que incorporou a tradição de Efraim e Manassés com a finalidade de colocar estas duas entidades à margem e enaltecer Judá.

Portanto, com o exposto acima, a tradução de Gn 49,22 que mais nos parece convincente é:

"Filho do touro é Efraim, filho do touro junto à fonte. Filho daquela que caminha a par do touro".

Isso coloca Gn 49,22 em sintonia com Dt 33,17, cujas unidades (Gn 49,2226 e Dt 33,13-17) estão bem próximas, para dizer que Efraim, a grande tribo de Israel Norte, se vangloriava por ser o primogênito do touro/Javé (Jr 31,9), posto que será disputado posteriormente por Judá (Gn 49,8-10; Cr 5,1-2)

Em resumo, os textos de Ex 32; 1Rs 12,26-33; Os 8,4-7; Dt 33,13-17 e Gn 49,22-26 revelam que em Israel, particularmente nos santuários de Betel, Dã e

\footnotetext{
${ }^{8}$ (Gn 41,50-52; 48; Nm 1,10.32; 13,11; 26,28.37; 27,1; 32,33; 34,23; 36,1.5.12; Js 14,4;16,1.4; 17,1-2.17).
} 
Samaria, mas, possivelmente também em outros santuários, como Siquém, era praticado um culto a uma divindade representado na imagem de um touro, a quem, em dado momento foi atribuída a libertação do Egito. Os textos apontam para o fato de que esta divindade no início era $\mathrm{El}$ e mais tarde será Javé, que passará a ser o Deus oficial de Israel, como comprova a estela de Mesa, onde, por volta de 840 a.C., Javé já aparece como o Deus de Israel Norte (KAEFER, J. A., 2006, p. 171-174). Portanto, antes de ser uma fonte inspiradora de resistência na luta contra os impérios estrangeiros em Judá, o Êxodo foi uma tradição de Israel Norte, similar à tradição do patriarca Jacó, oriunda também do norte, da região de Gilead, e que só mais tarde foi incorporada pela tradição de Judá, no sul, e associada à tradição do patriarca Abraão.

Se a tradição do Êxodo tem sua origem em Israel Norte, como ela surgiu? Em que contexto? Vejamos.

\section{A Campanha do Faraó Sheshong I}

Uma coisa parece evidente: a tradição do Êxodo nasce como forma de resistência ao domínio do império egípcio. E a última presença administrativa egípcia em Canaã foi durante a conhecida campanha do faraó Sheshong I (1Rs 14,25), por volta de 926 a.C, fato registrado nas muralhas do famoso templo de Karnak, no Egito. Muitas cidades do planalto central de Israel, como Gabaon e Betel, foram destruídas e abandonadas no início do ferro II (FINKELSTEIN, I., 2013, p. 51)9. Essa destruição coincide com a campanha do faraó Sheshong I (945925). A pergunta é: quem reinava sobre essas cidades do planalto central antes de serem destruídas por Sheshong? Uma vez que não foram Davi e Salomão (FINKELSTEIN, I.; SILBERMAN, N. A., 2006), uma hipótese possível é que tenha sido o reino de Saul, que estava por se firmar nesse período. Unicamente que se

\footnotetext{
9 "The Forgotten Kingdom", livro que está sendo traduzido ao português por um dos nossos alunos, Silas Klein, e que pronto será publicado pela editora Paulus.
}

Horizonte, Belo Horizonte, v. 13, n. 38, p. 878-906, abr./jun. 2015 - ISSN 2175-5841 
assim, então será preciso adiantar quase por um século o período do reinado de Saul (KAEFER, J. A., 2014, p. 161-165), que tradicionalmente é situado ao redor dos anos 1030-1010. Isso é possível, uma vez que a teoria da monarquia unida, sob Davi e Salomão, não se sustenta mais. Ou seja, Saul ocuparia o vácuo de poder que antes era atribuído a esses dois monarcas. Tal hipótese pode se apoiar nas recentes descobertas feitas no sítio arqueológico de Khirbet Qeiyafa (GARFINKEL, Y., GANOR, S., 2009).

É possível ler nesse viés a batalha decisiva no monte Gelboé entre Israel de Saul e os filisteus narrada em 1Sm 28-31. Essa batalha, na qual Saul e seus filhos perderam a vida, é considerada na literatura bíblica o marco do fim do reino de Saul. Ou seja, é provável que os filisteus estivessem a serviço dos egípcios de Sheshong I, com quem parece tinham relações comerciais, como o comércio de prata. E, em razão do constante conflito com os filisteus em tempos futuros, estes ficaram na memória do povo e dos redatores israelitas. A guerra, porém, teria sido de fato contra os egípcios de Sheshong I. É com esse sentido de luta contra os egípcios que o verbo 'lh "subir ou fazer subir"(hifil) era empregado na sua origem, como na frase vista acima: "Estes são teus Deuses, Israel, que te fizeram subir (lutar contra) da terra do Egito" (Ex 32,4b; 1Rs 12,28c). É assim que E. Zenger se expressa a respeito do significado do verbo ' $T h$ :

"A fórmula primitiva ( $l h$ ) provavelmente não se contentou com a ideia de uma simples caminhada sob o comando de Javé. Mas visava muito mais uma ação de Javé ligada ao combate e à guerra, tanto em relação ao ponto de partida (o Egito) quanto em relação ao ponto de chegada (Canaã). Foi só num estágio secundário que o significado, de origem tão concreta, da fórmula ( $l h$ ) foi estendido aos múltiplos eventos que demarcam o caminho do Egito para Israel” (ZENGER, E., 1996, p.241-241).

Depois da vitória sobre o nascente reino de Israel de Saul, a administração de Sheshong I se estabeleceu em Betsã, sítio que fica no coração do Vale de Jezreel, considerado o celeiro da região. A presença egípcia, contudo, não durou muito tempo. Os motivos são desconhecidos, mas sabe-se que o domínio egípcio foi substituído pelo novo reino de Israel, (FINKESLTEIN, I., 2013, p.146), que para 
esse tempo começa a criar status de estado e que se fortaleceu enormemente com a ascensão da dinastia omrida (884-842).

Portanto, é nesse contexto de luta contra a ocupação egípcia de Sheshong I que a tradição do Êxodo deve ter tido seu nascedouro, sendo preservada na memória popular inicialmente nos santuários de Betel e Siquém, na capital Tersa e depois também em Samaria.

Contudo, o que dizer da rota ou caminhada atribuída ao percurso do Êxodo? Isto é, se o Êxodo é uma tradição originária de Israel Norte, por que a rota do Êxodo seguiu pelo deserto ao sul de Judá, passando pela Transjordânia, Edom e Moab, e entrando na terra prometida pela região de Jericó, junto a Jerusalém? A resposta mais provável a essa pergunta é que o itinerário que o Êxodo seguiu teria sido acrescido mais tarde. Ou seja, o Êxodo enquanto luta contra o Egito e a caminhada pelo deserto são duas tradições independentes. Para o fundamento desta afirmação vamos nos apoiar na análise dos achados no sítio arqueológico Kuntillet 'Ajrud.

\section{Kuntillet 'Ajrud}

Kuntillet 'Ajrud foi um dos achados arqueológicos mais fantásticos da região do Sinai, sul do deserto de Judá, no final do século XX da nossa era. As inúmeras inscrições e desenhos ali encontrados, sem precedentes nas escavações do período da idade do ferro em Canaã, são essenciais para uma compreensão mais atualizada da história de Israel e Judá do século VIII a.C.

Kuntillet 'Ajrud fica no deserto do Sinai, a $50 \mathrm{~km}$ ao sul de Cades-Barnea e a $10 \mathrm{~km}$ a oeste da rústica via que liga Gaza a Elat. A pequena colina fica junto ao Wadi Quraya, que formava um caminho natural de leste a oeste, e onde, provavelmente, havia uma fonte permanente de água, caso raro nesta árida região 
do Sinai. O fator água fez de Kuntillet 'Ajrud parada obrigatória para as caravanas de comerciantes que iam e vinham, ligando o Egito à longínqua Arábia.

O sítio foi escavado por uma equipe coordenada pelo arqueólogo Ze'ev Meshel, do Instituto de Arqueologia da Universidade de Tel Aviv, em 1975-1976, e foi datado com bastante precisão na primeira metade do século VIII a.C. (MESHEL, Z., 1993). Portanto, com quase total probabilidade, durante o longo reinado de Jeroboão II (788-747).

As escavações encontraram duas áreas de construção, uma maior, retangular, e outra secundária. A construção maior continha um portão de entrada, um amplo pátio interno, uma sala em cada uma das quatro esquinas, e uma estreita sala retangular, à esquerda da entrada, paralela ao pátio interno. Nesta sala retangular foram encontradas várias pithoi, grandes jarras de cerâmica, utilizadas para armazenar grãos e azeite, sinal de que a sala era um grande armazém. A porta de entrada conduzia a uma primeira sala, conhecida como sala de entrada, que por sua vez conduzia a uma segunda sala, conhecida como sala dos bancos, e esta conduzia ao grande pátio interno.

Segundo Meshel, a sala dos bancos parece ter sido a sala mais importante da construção. Nela havia uma parede de gesso branco decorada, e ao longo da parede bancos de pedra, que ocupavam quase toda a sala. Na sala dos bancos foram encontradas duas pithoi decoradas, com inscrições e desenhos, além de várias tigelas de pedra, quatro delas com os nomes de seus doadores. No umbral da porta dos bancos foi encontrada parte de uma inscrição, o que faz lembrar o escrito no umbral da casa mencionado em Dt 6,9. Portanto, a sala de bancos parece ter sido um local religioso onde se guardavam os vasos e objetos oferecidos pelos fiéis que ali passavam pedindo bênção. Muitos vasos e potes de cerâmica, como as grandes pithoi, tinham letras cravadas, o que aponta para a hipótese de que Kuntillet 'Ajrud era um centro de coleta de tributos. As inscrições pedindo bênçãos e os potes de 
armazenagem de grãos mostram que em Kuntillet 'Ajrud a vida girava em torno de três elementos básicos: a água, o tributo e a bênção.

\subsection{Inscrições e desenhos}

Entre as inscrições e desenhos encontrados em Kuntillet 'Ajrud, dois grandes potes de cerâmica (pithoi) chamam especial atenção. Um pote foi encontrado na sala dos bancos e outro na sala lateral à direita, conhecida como sala das inscrições. Em ambos havia uma fórmula usada para introduzir uma carta-oração de bênção:

...o R(ei) diz: diga x, y, e z, que você seja abençoado por YHWH da Samaria e sua ASHERAH” (MESHEL, 1993, p. 208).

Entre os desenhos gravados nas jarras, alguns são mais notáveis, é o caso da cena que retrata duas divindades, aparentemente uma masculina e outra feminina. ${ }^{10}$ As divindades têm forma humana, mas com traços de animal, possivelmente de leão ou de touro. A parte superior do corpo está vestida com um vestuário de couro, e a parte inferior aparentemente está nua. O que parece ser a genitália, pode ser a cauda (do leão?). À parte tem outras cenas, um/a tocador/a de lira; uma árvore da vida ladeada por dois cabritos montanheses comendo das suas folhas; um leão; um grupo de pessoas (cinco figuras) com as mãos e erguidas em oração; um arqueiro atirando; um grupo de animais; e, por fim, uma vaca amamentando e lambendo seu filhote.

As duas divindades têm a cabeça, rosto, orelha, cabelo/juba parecidos com as de um leão, por isso foram logo identificadas com o Deus egípcio Bes. Se assim, a inscrição "YHWH da Samaria e sua Asherá" não estaria relacionada às duas figuras, seria uma inscrição independente (DAY, J., 2002, p. 51). Porém, a

\footnotetext{
${ }^{10}$ Infelizmente não é possível abordar aqui o extenso e fascinante tema do culto às divindades femininas em Canaã, como Asherá, e sua influência na cultura religiosa de Israel. Para tanto, há farta literatura, citamos alguma na bibliografia.
} 
diferença com as imagens ao Deus egípcio que conhecemos também é muito grande, de maneira que as dúvidas persistem. Por outro lado, nas duas divindades retratadas também há traços bovinos. Além disso, chama a atenção um detalhe: a divindade masculina tem seu pé dianteiro direito junto ao pé da vaca que está amamentando seu filhote, o que leva a supor que seja um touro.

Independentemente da identificação exata das imagens, a inscrição não deixa dúvida sobre dois fatos: Um, é que temos aqui mais uma prova consistente da existência de um culto a uma divindade identificada como "Javé da Samaria", capital de Israel Norte, como já visto nos textos bíblicos acima. E que, possivelmente, também aqui esse Javé é representado na imagem de um touro. Outra, de que o rei de Israel Norte, provavelmente Jeroboão II, era quem reinava em Kuntillet 'Ajrud e que, portanto, tinha o controle sobre a rota comercial EgitoArábia e seu rico tributo. Isso, evidentemente, arroga um grande poder a Israel Norte nessa primeira metade do século VIII, nada estranho para o narrador de 2Rs $14,25.28$.

Em meio aos fragmentos na sala dos bancos foram encontrados restos de três inscrições em caracteres fenícios. As inscrições foram feitas em tinta vermelha sobre o gesso que cobria a parede. $\mathrm{O}$ fato de o gesso ter se desapegado da parede $\mathrm{e}$ caído tornou praticamente impossível a reconstituição das inscrições. Também foram encontradas outras duas inscrições em hebraico antigo escrito em tinta preta entre os escombros da sala. Porém, somente parte da inscrição que estava no umbral da porta da sala dos bancos foi possível reconstituir. Apesar de fragmentária e desbotada, duas linhas foram reconstituídas e conformam o seguinte texto:

“... seus dias sejam prolongados e você esteja satisfeito... dê YHWH de Teman e sua ASHERAH...YHWH de Teman e sua ASHERAH favoreça...” (MESHEL, 1993, p. 207). 
Como vemos, o texto representa ser uma oração de bênção a ser dada ao viajante que depositava ali o seu tributo. Diferentemente do texto anterior, as divindades que abençoam aqui são Javé de Teman e sua Asherá.

Encontramos, em Kuntillet 'Ajrud, portanto, duas referências diferentes a Javé: Javé da Samaria e Javé de Teman. Um tema complexo, no entanto, não tão estranho como aparenta, pois essa referência encontra-se também em algumas passagens bíblicas, como em Dt 33,2; Jz 5,4-5 e Hab 3,3.7. Esses textos parecem indicar que Javé tem sua origem da região desértica do sul de Edom ou norte da Arábia. Os textos mencionados se referem a Javé como um Deus da montanha e em movimento, similar ao sol, de leste a oeste. De maneira que, é provável que Javé não seja originário de Canaã (DAY J., 2002, p. 15). Um fator determinante para essa possibilidade é o fato de que Javé não aparece na lista do panteão ugarítico, cujo imaginário religioso influenciou enormemente o contexto cananeu (Sl 82). Ultimamente a tendência dos pesquisadores é situá-lo como provindo de fora, da região de Madiã, na Arábia. Da mesma forma, a localização do monte Sinai, não seria na Península do Sinai, ao sul do deserto de Judá, mas no sul da Transjordânia ou noroeste da Arábia (CROS, F. M., 1988, p. 46-65). As inscrições de Kuntillet ‘Ajrud parecem dar suporte a essa hipótese.

Esse fato, no entanto, conduz a outro problema. Se os textos bíblicos ainda trazem a memória de Javé como sendo originário de fora, hipótese que é corroborada pelas inscrições extra-bíblicas, então o culto a Javé em Canaã é relativamente jovem. Apesar de que, como vimos acima, no tempo dos omridas Javé já ser o Deus nacional de Israel Norte, é possível, e nos parece ser assim, que o Deus a quem inicialmente era atribuída a libertação do Egito não era Javé, mas El, vejamos. 


\subsection{El e Javé}

O que é evidente na literatura bíblica mais antiga da Bíblia Hebraica, bem como nas escavações arqueológicas, é a forte presença do culto a El em Canaã. Basta observar a presença da raiz el no nome de pessoas e de lugares na Bíblia. Inclusive no nome próprio “Israel”. No panteão ugarítico, El era o Deus supremo e seu símbolo era o touro (DAY. J, 2002, p. 34-39). A fertilidade, no entanto, parece que não era atributo de El, pelo menos não o principal, esta era bem mais atributo de Baal. De forma que, o touro associado a Javé, visto nos textos de nossa análise, é uma herança de El, a divindade suprema do panteão ugarítico. Portanto, o grande número de imagens ou símbolos associados ao touro, como o vaso de cerâmica em forma de touro encontrado em Silo, a estatueta de prata do touro jovem encontrada em Asquelon, a famosa imagem do touro encontrada em Siquém, perto de do monte Ebal, cujo sítio arqueológico passou a ser conhecido como "sítio do touro" (DAY, J., 2002, P. 34, n.58), era referência a El.

Há, no entanto, praticamente um consenso entre os pesquisadores, de que Javé se apropriou dos atributos de El. O touro que antes era a representação de El, agora será Javé. Evidentemente que aqui estamos nos referindo a Javé da Samaria, como visto acima, forma que será duramente criticada pelos redatores deuteronomistas de Jerusalém. Essa apropriação também se deu referente a Baal, com a diferença de que com Baal a apropriação aconteceu em meio a forte disputa, basta ver, entre os vários exemplos, Os 1-3, enquanto que com El parece ter sido mais pacífica. Ou seja, se uma das grandes apropriações de Javé foi a consorte de El, Asherá (DEVER, W. G. 2005), a outra foi o touro. Evidentemente que o conflito não é entre as divindades, mas é a forma como aos poucos os atributos de um Deus passam a ser atribuídos pelos fiéis a outro Deus. Esse é um processo constante na história do fenômeno religioso.

Assim, é provável que antes de ser associado a Javé, o Êxodo era atribuído a El. Isso, a nosso ver é confirmado por Nm 23,22 e 24,8, onde a libertação do Egito 
é atribuída a El, que é associado ao touro. Assim dizem estes versos: "El, o que tira eles do Egito, seus chifres são como os de touro selvagem ( $\left.r^{\prime} m\right)$ ” (Nm 23,22); "El, o que tira ele do Egito, seus chifres são como os de touro selvagem" (Nm 24,8). Os dois versos são de tradução difícil, e não está claro se o complemento "seus chifres" se refere a El ou a Israel. Em todo caso, "El”, "Israel", "chifres" e "touro selvagem" pertencem ao mesmo campo semântico.

\subsection{Kuntillet 'Ajrud e a memória da caminhada no deserto'11}

Como afirmado anteriormente, a caminhada pelo deserto é uma tradição independente da tradição do Êxodo e ela foi acrescida mais tarde a esta. Os locais citados na rota do Êxodo deviam ser desconhecidos de Israel Norte no século X, quando nasce a tradição do Êxodo, muitos deles, inclusive, eram inexistentes (FINKESTEIN, I., 1999). Ou, pelo menos, se havia algum conhecimento esse era muito fragmentário. No entanto, pelo século VIII, Oséias e Amós já tinham ciência da tradição da caminhada pelo deserto. ${ }^{12}$ Assim sendo, como foi que a rota pelo sul da Península do Sinai, até o Golfo de Ácaba e subindo pela Transjordânia, passando por Edom até Moab chegou a ser conhecida por Israel Norte no século VIII a ponto de ser mencionada pelos profetas? É possível que Kintillet 'Ajrud possa ser a chave para a compreensão desta complexa questão.

Pelo visto acima a respeito dos achados em Kuntillet 'Ajrud, está comprovado que Jeroboão II (788-747), rei de Israel Norte, dominava sobre a Península do Sinai até o Golfo de Ácaba na primeira metade do século VIII. ${ }^{13}$ E que Israel controlava a rota comercial que ligava a Arábia com o Egito através do deserto do Sinai. Conforme Nadav Na'aman, um desenho encontrado no muro de entrada da principal construção de Kuntillet 'Ajrud parece fazer menção à rota do

\footnotetext{
${ }^{11}$ Para esse assunto só podemos arguir hipoteticamente e, para tanto, nos inspiramos prioritariamente numa conferência apresentada por Israel Finkelstein em novembro de 2013, em San Diego, Baltimore.

${ }^{12}$ Os 2,16-17; 9,10; 11,1-5; 12,10.14; 13,4-5; Am 2,10; 3,1; 9,7.

${ }^{13}$ Período em que, provavelmente, Ozias (781-840), rei de Judá (2Rs 15,1-7), foi vassalo de Jeroboão II.
} 
Êxodo, ${ }^{14}$ o que mostraria que a tradição do Êxodo não só era conhecida em Israel Norte, mas era utilizada como propaganda pela realeza de Samaria e já era difundida no sul de Judá. É possível que o itinerário do Êxodo narrado em Nm 33 tenha surgido nesse momento e nesse contexto, pois Nm 33 apresenta locais que só aparecem aqui e que não são citados em outros textos que tratam do Êxodo. ${ }^{15}$ Em Kuntillet 'Ajrud as autoridades e escribas de Israel Norte certamente tinham contato constante com comerciantes nômades e com eles devem ter aprendido sobre lugares do deserto distante, desde o Golfo de Ácaba até a costa do Mediterrâneo, esses poderiam ter sido os nomes que aparecem na lista de Nm 33 . Portanto, a lista de nomes de Nm 33 seria a fonte mais antiga da caminhada do deserto e independente das demais. Sua origem estaria ligada a informações de comerciantes e peregrinos que passavam por Kuntillet 'Ajrud.

Entendendo melhor, a tradição da caminhada pelo deserto teria se originado em Kuntillet 'Ajrud, durante a primeira metade do século VIII, quando Israel Norte dominava a Península do Sinai. De lá teria migrado para a Samaria, onde teria sido integrada à tradição do Êxodo e encorpada a propaganda antiEgito. É nesse sentido que ela é mencionada pelos profetas Oseias e Amós. Depois da queda da Samaria, em 722, a tradição do Êxodo, já com a caminhada pelo deserto integrada, migrou para Judá, juntamente com outras tradições provenientes de Israel Norte, e ali ela é incluída na história da lei de Moisés. Com a queda da Assíria na segunda metade do séc. VII, ficou um vácuo de poder na região da Península do Sinai, que passa a ser disputada por Judá e Egito, este sob o reinado da vigésima sexta dinastia (663-525). ${ }^{16}$ É possível que o conflito se desse também com o reino de Edom, que também tinha interesses na região.

Para Judá, no tempo do rei Josias (640-609) a tradição do Êxodo cai como uma luva na luta contra o Egito, principalmente pelo fator ideológico da vitória de

\footnotetext{
${ }^{14}$ NA'AMAN, Nadav. The Inscriptions of Kuntillet 'Ajrud trough the Lens of Historical Research. Ugarit-Forschungen, 43 (2012a), Neukirchen-Vluyn, p. 1-43.

${ }^{15}$ A maioria desses locais continua desconhecida.

${ }^{16}$ É importante lembrar que por volta de 650 a.C. os assírios são expulso do Egito, que a partir de então começa a expandir seus domínios sobre os antigos territórios cananeus, conflitando com o nascente reino judaíta. É nesse contexto que deve ser lida a morte do rei Josias pelo faraó Necao, em Megiddo, em 609 a.C. (2Rs 23,29).
} 
Javé sobre o faraó. Nesse tempo, com amplo conhecimento por parte dos escribas jerusalemitas da região sul de Judá e de suas rotas, a caminhada pelo deserto é ampliada e detalhada. É provável que a peregrinação pelo deserto do Negev, passando pela fortaleza de Cades Barnea, tenha sido acrescentada nesse período, pois as escavações nesta região, particularmente em Cades Barnea, mostram forte presença do domínio dos reis de Judá nestes locais durante a monarquia tardia. É possível que a importância de Edom e Moab no itinerário do Êxodo reflita também esse período.

Segundo Israel Finkelstein ${ }^{17}$, o conhecimento geopolítico dos locais da rota do Êxodo dos judeus desapareceu no final da idade do ferro. Todas as fortalezas do deserto foram abandonadas e Edom declinou depois do sec. V. Os sacerdotes que escreveram no pós-exílio não tinham mais conhecimento desses lugares do sul do deserto. Portanto, os lugares mencionados na rota do Êxodo só podem ser oriundos de tempos pré-exílicos. Contudo, a narrativa do Êxodo continuou a se desenvolver, principalmente no resgate da identidade do povo judaíta após o exílio da Babilônia, fazendo uma releitura da antiga tradição para um Novo Êxodo.

\section{Conclusão}

O Estudo dos textos bíblicos de Ex 32; 1Rs 12,26-33; Os 8,4-7; Dt 33,13-17 e Gn 49,22-26 revela que em Israel Norte havia uma tradição que atribuía a libertação do Egito a uma divindade cultuada na forma de touro. Possivelmente essa tradição surgiu na luta contra a ocupação egípcia durante a campanha do faraó Sheshong I, registrada no templo de Karnak, no Egito, quando o nascente reino de Israel Norte foi derrotado pelas forças egípcias (1Sm 31). Vimos ainda que os textos analisados deixam a entender que a divindade cultuada na forma de touro era Javé. Esse atributo, porém, pertencia anteriormente a El, a divindade suprema do panteão ugarítico, com forte presença também em Canaã. Portanto, no

\footnotetext{
${ }^{17}$ The Forgotten Kingdom, p. 150.
} 
início o Deus do Êxodo em Israel Norte era El, cultuado na imagem de um touro nos santuários de Betel e Siquém, entre outros, e só mais tarde passou ser Javé, que absorveu os atributos de El.

Num segundo momento abordamos a tradição da caminhada pelo deserto, tradição independente que só mais tarde foi associada à tradição da libertação do Egito. Nesse particular nos apoiamos nas descobertas arqueológicas de Kuntillet 'Ajrud, as quais mostram que na primeira metade do século VIII, Israel Norte, com Jeroboão II, reinava sobre a região sul de Judá até o porto de Ácaba e que, portanto, controlava a rota comercial que passava pelo Sinai ligando o norte da Arábia com a costa do Mediterrâneo e o Egito. Foi visto que em Kuntillet 'Ajrud havia um culto a Javé da Samaria e sua Asherá, bem como a Javé de Teman, nordeste da Arábia, e sua Asherá. É possível que a tradição da caminhada no deserto tenha surgido nesse local e nesse período, quando os escribas de Israel Norte atuantes em Kuntillet 'Ajrud tomaram conhecimento dos lugares da rota do Êxodo através de comerciantes e de peregrinos que passavam por Kuntillet 'Ajrud. Foi assim que tradição do Êxodo: libertação e caminhada chegou até os profetas Oseias e Amós. É possível que essa rota seja a que menciona Nm 33, cujos lugares são em sua maioria desconhecidos e diferentes dos lugares citados por outros textos bíblicos.

Depois de migrar de Kuntillet 'Ajrud para a Samaria, as duas tradições se fundiram e, juntamente com outras tradições, migraram para o sul, Jerusalém, após a queda da Samaria, em 722 a.C. Em Judá, agora já como tradição do Êxodo, recebeu adendos e foi amplamente utilizada na luta do rei Josias contra o Egito da vigésima sexta dinastia. No exílio e pós-exílio, o Êxodo foi reelido, agora como novo Êxodo, e serviu de referência para a reconstrução da identidade judaíta. 


\section{REFERÊNCIAS}

BENITEZ, Milton Acosta. La Estela de Merneptah y la tasa de desempleo: ideología y teología en la historiografía de los orígenes de Israel. Theológica Xaveriana, Bogotá, v. 63, n. 176, p. 307-330, 2013.

CROATTO, Severino. A deusa Aserá no antigo Israel: a contribuição epigráfica da arqueologia. Revista de Interpretação Bíblica Latino-Americana (RIBLA), n. 38. Petrópolis: Vozes, 2002. p. 32-44.

CROSS, F. M. Reuben: first-born of Jacob. ZAW supplement, Erlangen, v. 100 , issue s1, p. 46-65, 1988.

DAY, John. Yahweh and the Gods and Goddesses of Canaan. New York: Sheffield Academic Press, 2002. (JSOT Supplement Series, 265).

DE PURY, A. (Org.). O Pentateuco em questão: as origens e a composição dos cinco primeiros livros da Bíblia à luz das pesquisas recentes. Petrópolis: Vozes, 1996.

DEVER, William G. Did God have a wife? archaeology and folk religion in ancient Israel. Michigan: Eerdmans, 2005.

FINKELSTEIN, I.; MAZAR, Amihai. The quest for the historical Israel: debating archaeology and the history of early Israel. Edição Brian B. Schmidt. Atlanta: SBL, 2007.

FINKELSTEIN, I.; SILBERMAN, N. A. David and Solomon: In search of the Bible's sacred kings and the roots of the western tradition. New York: The Free Press, 2006.

FINKELSTEIN, I.; SILBERMAN, N. A. The Bible unearthed: archaeology's new vision of ancient Israel and the origin of its sacred texts. New York: The Free Press, 2001.

FINKELSTEIN, I. State formation in Israel and Judah: a contrast in context, a contrast in trajectory. Near Eastern Archaeology, Boston, v. 62, n. 1, p. 35-62, 1999.

FINKELSTEIN, I. The forgotten kingdom: the archaeology and history of northern Israel. Atlanta: SBL, 2013.

FINKELSTEIN, I. Two notes on northern Samaria: the "Einun Pottery and the date of the 'Bull Site”. Palestine Exploration Quarterly, London, v. 130, p. 94-98, 1998.

FLEMING, D. E. The legacy of Israel in Judah Bible: history, politics and the reinscribing of tradition. Cambridge: Cambridge University Press, 2012. 
GARFINKEL, Y.; GANOR, S., Khirbet Qeiyafa: Excavation Report 2007-2008. Jerusalem: Israel Antiquities Authority, 2009.

GERSTENBEGER, Erhard S. Teologias no Antigo Testamento: pluralidade e sincretismo da fé em Deus no Antigo Testamento. São Leopoldo: Sinodal, 2008.

GUNKEL, H. Genesis. Göttingen: Vandenhoeck \& Ruprecht, 1964.

HOOP, R. De. Genesis 49 in its literary and historical context. Leiden: Brill, 1999.

ISHIDA, T. The house of Ahab. Israel Exploration Journal, Jerusalem, v. 25, p. 135137, 1975 .

KAEFER, José Ademar. A estela de Dã. Caminhando, São Bernardo do Campo, v. 17, n. 2, p. 33-46, jul./dez. 2012.

KAEFER, José Ademar. Arqueologia das terras da Bíblia. São Paulo: Paulus, 2012.

KAEFER, José Ademar. Hermenêutica bíblica: refazendo caminhos. Estudos da Religião, São Bernardo do Campo, v. 28, n. 1, p. 115-134, jan./ jun. 2014.

KAEFER, José Ademar. Tribalismo na história de Israel: perspectiva ainda válida? Revista Espaços, São Paulo, v.18, n.2, p. 169-177, 2010.

KAEFER, José Ademar. Un Pueblo libre y sin reyes: la función de Gn 49 y Dt 33 en la composición del Pentateuco. Estella: Editorial Verbo Divino, 2006.

KEEL, Othmar; UEHLINGER, Christoph. Göttinnen, Götter und Gottessymbole: Neue Erkenntnisse zur Religionsgeschichte Kanaans und Israels aufgrund bislang unerschlossener ikonographischer Quellen. Friburgo: Herder, 1992.

KORPEL, M. C. A. A rift in the clouds: Ugaritic and Hebrew descriptions of the divine. Münster: Ugarit - Verlag, 1990.

MACCHI, J. D. Israël et ses tribus selon Genèse 49. Göttingen: Vandenhoeck \& Ruprecht, 2001.

MAZAR, A. The "Bull Site": An Iron Age I Open Cult Place. Bulletin of the American Schools of Oriental Research, Boston, n.247, p. 27-42, Summer 1982.

MESHEL, Z.; CARMI, I.; SEGAL, D. 14C Dating of an Israelite biblical site at Kuntillet Ajrud. Radiocarbon, Tucson, v. 37, n. 2, p. 205-212, 1993.

MIELE, Neide. Origem pagã do conceito de messias. In: MARQUES, Luiz Carlos Luz (Org.). Religiosidades populares e multiculturalismo: intolerâncias, diálogos, interpretações. Recife: Editora Universitária UFPE, 2010. p. 143-165. 
NA'AMAN, Nadav. Ancient Israel's history and historiography: the first temple period. Winona Lake: Eisenbrauns, 2006.

NA'AMAN, Nadav. Khirbet Qeiyafa in context. Ugarit-Forschungen, NeukirchenVluyn, v. 42, p. 497-526, 2006.

NA'AMAN, Nadav. The abandonment of cult places in the kingdoms of Israel and Judah as acts of cult reform. Ugarit-Forschungen, Neukirchen-Vluyn, v. 34, p. 585-602, 2002.

NA'AMAN, Nadav. The Exodus history: between historical memory and historiographical composition. Journal of Ancient Near Eastern Religions, Chicago, v. 11 , n. 1, p. 3969, 2011.

NA'AMAN, Nadav. The inscriptions of Kuntillet 'Ajrud through the lens of historical research. Ugarit-Forschungen, Neukirchen-Vluyn, v. 43, p. 1-43, 2012.

NOVA BÍBLIA PASTORAL. São Paulo: Paulus, 2014.

OTTERMANN, Monika. A Deusa Inana-Ištar - uma rival de YHWH? Considerações feministas em torno das Deusas-Árvore e do Deus único da Bíblia Hebraica. In: REIMER, Haroldo; SILVA, Valmor da (Org.). Hermenêuticas Bíblicas: contribuições ao I Congresso Brasileiro de Pesquisa Bíblica. Goiânia: Editora UCG, 2006. p. 136-147.

OTTERMANN, Monika. "Eu sou tua Anat e Aserá...”. YHWH e Aserá (não só) no Livro de Oséias: profecia e esperança: um tributo a Milton Schwantes. São Leopoldo: Oikos, 2006.

PRITCHARD, J. B. (Ed.). The ancient near eastern texts relating to the Old Testament (ANET). New Jersey: Princeton University Press, 1969.

REIMER, Haroldo. Inefável e sem forma: estudos sobre o monoteísmo hebraico. Goiânia: Editora UCG, 2009.

REIMER, Ivoni Richter (Org.). Imaginários da divindade. Goiânia: Editora UCG, 2008.

RÖMER, Thomas. A chamada história deuteronomista. Vozes: Rio de Janeiro, 2008.

SALO, V. Joseph, der Sohn der "Färse”. Biblische Zeitschrift, 12. Paderborn, p. 94-95, 1968.

SANMARTÍN, J. Problemas de textología en las «Bendiciones» de Moisés (Dt 33) y de Jacob (Gn 49). In: COLLADO, V.; ZURRO, E. (Org.). El mistero de las palabras: FS L.A. Schökel. Madrid: Cristiandad, 1983. p. 75-96. 
SCHOORS, A. The kingdoms of Israel and Judah in the eighth and seventh centuries B.C.E. Atlanta: SBL, 2013.

SCHULTE, $\mathrm{H}$. The end of the Omride dynasty: social-ethical observations on the subject of power and violence. KNIGHT, D. A. (Org.). Ethics and politics in the Hebrew Bible. Atlanta: Scholars, 1994. p. 33-148.

SEEBASS, H. Die Stämmesprüche Gn 49, 3-27. ZAW supplement, Erlangen, v. 96, n. 3, p. $333-350,1984$.

SMITH, Mark S. O memorial de Deus: história, memória e a experiência do divino no Antigo Israel. São Paulo: Paulus, 2006.

SMITH, Mark S. The early history of God: Yahweh and the other deities in ancient Israel. Michigan: Wm. B. Eerdmans Publishing Co., 2002.

SPEISER, E.A. Genesis: a new translation with introduction and commentary. Garden City: 1964.

SCHWANTES, M. História de Israel: Local e origens. $4^{\text {a }}$. edição. São Leopoldo: Oikos, 2008.

WENNING, R.; ZENGER, E. Ein Bäuerliches Baal-Heiligtum im samarischen Gebirge aus der Zeit der Anfänge Israels. ZDPV, Lichtenstein, v. 102, p. 75-86, 1986.

WESTERMANN, C. Genesis 37-50. Neukirchen-Vluyn: Neukirchener Verlag, 1982.

WHITT, William D. The divorce of Yahweh and Asherah in Hos 2, 4-7. $12 \mathrm{ff}$.

Scandinavian Journal of the Old Testament, Copenhagen, v. 6, n. 1, p. 31-67, 1992.

WILliamson, H. G. M. Tel Jezreel and the dynasty of Omri. Palestine Exploration Quarterly, London, v. 128, n.1, p. 41-51, 1996.

ZENGER, E. O tema da "saída do Egito" e a origem do Pentateuco. DE PURY, A. (Org.). O Pentateuco em questão: as origens e a composição dos cinco primeiros livros da Bíblia à luz das pesquisas recentes. Petrópolis: Vozes, 1996. p. 240-269.

ZOBEL, H. J. Stammesspruch und Geschichte. Die Angaben von Gen 49, Dtn 33 und Jdc 5 über die politischen und kultischen Zustände im damaligen „Israel“. BZAW, Berlin, v. 95, 163 p. 1965. 